\title{
A systematic review of the cardiovascular risk of inhaled anticholinergics in patients with COPD
}

This article was published in the following Dove Press journal:

International Journal of COPD

29 June 2009

Number of times this article has been viewed

\section{Daniel E Hilleman' \\ Mark A Malesker' \\ Lee E Morrow ${ }^{2}$ \\ Dan Schuller ${ }^{2}$}

'Department of Pharmacy Practice, Creighton University School of Pharmacy and Health Professions, Omaha, Nebraska, USA; ${ }^{2}$ Division of Pulmonary and Critical Care Medicine, Creighton University School of Medicine, Omaha, Nebraska, USA
Correspondence: Daniel E Hilleman Creighton University School of Pharmacy and Health Sciences, Department of Pharmacy Practice, 2500 California Plaza, Omaha, NE 68I78, USA Email hilleman@creighton.edu
Abstract: The long-term use of inhaled anticholinergic agents has recently been suggested to be associated with an excess risk of adverse cardiovascular (CV) outcomes in patients with COPD. We identified 15 published studies that reported on the association between long-term inhaled anticholinergic use and adverse CV outcomes. Only 3 of the studies were adequately designed randomized controlled trials (RCTs). The first RCT that suggested that anticholinergic agents increased the risk of adverse CV outcomes was the Lung Health Study (LHS). Smokers randomized to inhaled ipratropium had a significantly increased risk of $\mathrm{CV}$ death than smokers receiving placebo. The LHS results have been questioned as the statistical tests used in the study were not adjusted for multiple tests and endpoints, a convincing dose-effect relationship between ipratropium use and the adverse CV outcomes was not established, and most of the CV deaths in the ipratropium group occurred in patients who were non-compliant to ipratropium. The Investigating New Standards for Prophylaxis in Reducing Exacerbations (INSPIRE) was a RCT that compared the combination of salmeterol plus fluticasone against tiotropium in patients with COPD. All-cause mortality was significantly lower in the salmeterol plus fluticasone group (3\%) compared to the tiotropium group (6\%). Fatal CV events occurred in $1 \%$ of the salmeterol plus fluticasone group compared to $3 \%$ in the tiotropium group. The INSPIRE trial was not designed to be a mortality trial, lacked adequate adjudication of fatal outcomes, and lacked a full intention-to-treat analysis of the data. The Understanding Potential Long-Term Impacts on Function with Tiotropium (UPLIFT) trial was a RCT comparing tiotropium and placebo in patients with COPD. Follow-up in UPLIFT was planned for 1440 days (4 years) plus 30 days (1470 days) of post-treatment follow-up. At 1440 days with $95 \%$ of patient outcome accounted for, tiotropium was associated with a significant $13 \%$ reduction in all-cause mortality compared to placebo. However, at 1470 days with only $75 \%$ of patient outcome accounted for, tiotropium was associated with a non-significant $11 \%$ reduction in all-cause mortality compared to placebo. The relative risks for serious $\mathrm{CV}$ events, heart failure, and myocardial infarction were all significantly lower with tiotropium than placebo. It is not certain why such a wide disparity in findings exists among the published studies evaluating the CV risks of inhaled anticholinergic agents. Prospective, adequately powered RCTs are needed to provide more evidence for the CV safety of tiotropium.

Keywords: COPD, anticholinergics, cardiovascular risk, evidence-based guidelines

\section{Evidence-based treatment guidelines}

Evidence-based guidelines for the management of chronic obstructive pulmonary disease (COPD) were first developed by the National Heart, Lung, and Blood Institute and the World Health Organization, the Global Initiative for Chronic Obstructive Lung Disease (GOLD). ${ }^{1}$ Since then, the GOLD has been updated and revised and additional 
guidelines have been published by the American Thoracic Society, the European Respiratory Society, the Canadian Thoracic Society, and the National Institute for Clinical Excellence with the purpose of improving the prevention, diagnosis, and management of COPD. ${ }^{2-5}$

The goals of treatment in patients with COPD are to relieve symptoms, prevent disease progression, reduce the frequency and severity of exacerbations, improve health status, improve exercise tolerance, and reduce mortality. Ideally, these therapeutic goals should be realized with minimal side effects from treatment, a difficult challenge in COPD patients because of their high incidence of comorbidities. All of the guidelines agree that bronchodilators are a mainstay of therapy for patients with COPD. Currently available bronchodilators include beta-2 agonists, anticholinergics, and methylxanthines. Short-acting bronchodilators are recommended for relief of symptoms on an as needed basis while long-acting bronchodilators are recommended to be given on a regularly scheduled basis for persistent symptoms. Inhaled bronchodilators are also generally preferred over oral agents in order to minimize systemic exposure and side effects. Hence, the initial selection of a long-acting bronchodilator typically includes a beta- 2 agonist or an anticholinergic rather than a methylxanthine. The guidelines do not specify which type of bronchodilator is preferred for the initial management of COPD. The use of combinations of bronchodilators is recommended for patients with persistent symptoms not controlled following the use of a single bronchodilator. As a result, many patients are receiving both beta-2 agonists and anticholinergics. In patients with severe COPD experiencing frequent exacerbations despite the use of one or more bronchodilators, the addition of inhaled corticosteroids is recommended.

In March 2008, the FDA issued an "early warning" communication which stated that Boehringer Ingelheim (the manufacturer of tiotropium) had conducted a pooled analysis of 29 trials which found an increased risk of stroke with tiotropium ( 8 cases per 1000) compared to placebo (6 cases per 1000). ${ }^{6}$ In September 2008, a meta-analysis published in JAMA reported a significantly increased risk of cardiovascular mortality with inhaled anticholinergics. ${ }^{7}$ The results of this meta-analysis and the "early warning" communication from the FDA has raised concerns about the routine use of inhaled anticholinergic agents in patients with COPD.

The purpose of this systematic review is to evaluate the currently available evidence concerning the efficacy and safety of the long-term use of inhaled anticholinergic agents in patients with COPD. All clinical studies of inhaled anticholinergic agents in patients with COPD were identified through a computerized literature search using the following databases: PubMed 1950-2009; Ebsco Host 1950-2009; and The Cochrane Central Register of Controlled Trials 1996-2009 in the Cochrane Library. The key terms used included ipratropium, tiotropium, formoterol, salmeterol, inhaled corticosteroids, cardiovascular events, morbidity, mortality, and COPD. Identified studies were evaluated and grouped according to their conclusions on the relationship between inhaled anticholinergic agents and adverse cardiovascular outcomes.

\section{Evidence that anticholinergics increase adverse cardiovascular outcomes}

Singh et al performed a meta-analysis designed to evaluate the risk of major adverse cardiovascular events with inhaled anticholinergic agents in patients with COPD. ${ }^{7}$ Trials were included if they were randomized and controlled using any inhaled anticholinergic agent (ipratropium or tiotropium) with 30 days or more of follow-up. Study participants could have a COPD diagnosis of any severity. Trials including patients with asthma were excluded. The control group could include placebo or an active control (inhaled beta-agonist or inhaled beta-agonist combination). The trials had to report the incidence of serious cardiovascular events including myocardial infarction, stroke and cardiovascular death.

A total of 103 trials were reviewed in detail with 17 (12 with tiotropium and 5 with ipratropium) trials meeting the inclusion criteria. Of the 86 trials excluded from the analysis, 69 were excluded as they did not report adverse cardiovascular events, two trials reported a zero incidence of events in both treatment groups, and 15 were not randomized, controlled trials of anticholinergic versus control lasting longer than 30 days.

In the 17 trials, a total of 14,783 patients were included in which 7472 received an anticholinergic agent and 7311 received a control therapy. Nine trials compared inhaled anticholinergics with placebo and 8 included an active comparison (salmeterol in 6 trials, salmeterol/fluticasone in trial and albuterol in 1 trial). Five trials were long-term ( $>6$ months to 5 years) and 12 were short-term ( 6 weeks to 6 months). The mean $\mathrm{FEV}_{1}$ was $<50 \%$ in all but one trial in which the mean $\mathrm{FEV}_{1}$ was $75 \%$. All trials were doubleblind while allocation concealment was adequate in 4 trials and not stated in 13 trials. Rates of patient withdrawal were available for all but one trial and ranged from $6 \%$ to $42 \%$. Outcomes reported in these trials included all-cause mortality 
in all 17 trials $(\mathrm{n}=14,783)$, cardiovascular death in 12 trials $(\mathrm{n}=12,376)$, myocardial infarction in 11 trials $(\mathrm{n}=10,598)$ and stroke in 7 trials $(\mathrm{n}=9251)$.

Inhaled anticholinergics significantly increased the risk of the composite outcome of cardiovascular death, myocardial infarction, or stroke ( $1.8 \%$ vs $1.2 \%$ for controls; relative risk [RR] 1.58 [95\% confidence interval (CI) 1.21-2.06] $P<0.001)$. Inhaled anticholinergics increased the risk of myocardial infarction ( $1.2 \%$ vs $0.8 \%$ for controls; RR 1.53 [95\% CI 1.05-2.23] $P=0.03$ ) and cardiovascular death ( $0.9 \%$ vs $0.5 \%$ for controls; RR 1.80 [95\% CI 1.17-2.77] $P=0.008)$. Inhaled anticholinergics did not significantly increase the risk of stroke $(0.5 \%$ vs $0.4 \%$ for controls; RR 1.4 [95\% CI 0.81-2.62]; $P=0.20$ ). Inhaled anticholinergics did not significantly increase the risk of all-cause mortality (2.0\% vs $1.6 \%$ for controls; RR 1.26 [95\% CI 0.99-1.61] $P=0.06)$. In a sensitivity analysis limited to the 5 longterm trials, the adverse effect of inhaled anticholinergics persisted (RR $1.73 ; P<0.001$ ). There was no statistically significant increase in the risk of cardiovascular death, myocardial infarction, and stroke in a sensitivity analysis of the 12 short term trials (RR 1.16; $P=0.60$ ). The adverse effect also persisted when the tiotropium trials (RR 2.12; $P=0.008)$ were separated from the ipratropium trials (RR $1.57 ; P=0.02$ ).

This meta-analysis has a number of methodological flaws which raise concerns about the validity of its conclusions. ${ }^{8}$ The meta-analysis combined placebo-control studies with active-control studies. The numbers of patients and adverse clinical events in two of the trials included in the metaanalysis were incorrectly reported. One study included in the meta-analysis was a duplicate publication of another study already included in the meta-analysis effectively leading to double counting of approximately 1000 patients in the analysis. Differences in patient exposure and discontinuation rates were not accounted for in the meta-analysis. In most of the trials, a higher rate of premature treatment discontinuation occurred in the placebo groups compared to the active treatment. A substantial proportion of the overall number of patients included in the meta-analysis came from a single trial, the Lung Health Study (LHS). A retrospective analysis found that most of the cardiovascular deaths in the LHS occurred in patients who were non-compliant with their inhaled anticholinergic agent (ipratropium).

The earliest published study to suggest an adverse cardiovascular effect of inhaled anticholinergic agents in patients with COPD was the LHS. ${ }^{9}$ The LHS randomized 5887 smokers who did not consider themselves ill but who had mild to moderate lung function impairment to one of three groups: (1) smoking cessation with ipratropium; (2) smoking cessation without ipratropium (placebo); and (3) usual care. Patients were followed for 5 years. There were no significant differences in mortality or hospitalizations between the usual care group and either of the two smoking cessation groups. However, death due to cardiovascular disease was significantly greater in the smoking cessation plus ipratropium group compared to the smoking cessation plus placebo group $(P=0.027)$. Coronary heart disease deaths and the combination of fatal/nonfatal cardiovascular disease deaths were more frequent in the smoking cessation plus ipratropium group compared to the smoking cessation plus placebo group, but the differences between the groups did not reach statistical significance ( $P=0.084$ and $P=0.156)$. The statistical tests used were not adjusted for multiple tests and endpoints. In addition, the investigators were not able to demonstrate a convincing dose-effect relationship between ipratropium and the adverse cardiovascular outcomes. Most of the cardiovascular deaths occurring in the ipratropium group occurred among patients not compliant with their ipratropium. The investigators concluded that despite the higher rates of coronary and cardiovascular events and deaths in the ipratropium group, they were not able to prove or disprove that the difference in outcomes occurred due to a drug effect. They recommend that an adequately powered study be conducted to confirm or refute their findings and to investigate the possible mechanisms of such an effect.

The LHS was obviously not able to determine a possible mechanism of the adverse cardiovascular effect of ipratropium, but there was a higher frequency of hospitalizations for supraventricular tachycardia (SVT) in the smoking cessation plus ipratropium group compared to the smoking cessation plus placebo group. Even though the frequency of hospitalization for SVT was uncommon, a dose-effect relationship between ipratropium use and SVT requiring hospitalization was observed. Whether episodes of SVT or other arrhythmias not resulting in hospitalization led to a higher rate of myocardial ischemia or other adverse cardiovascular outcome in the LHS cannot be determined.

The Investigating New Standards for Prophylaxis in Reducing Exacerbations (INSPIRE) trial randomized 1323 COPD patients to salmeterol/fluticasone 50/500 $\mu \mathrm{g}$ twice daily $(\mathrm{n}=658)$ or to tiotropium $18 \mu \mathrm{g}$ daily $(\mathrm{n}=665) .{ }^{10}$ The study was a 2-year multicenter, randomized, doubleblind, double-dummy trial with a primary efficacy endpoint of COPD exacerbations. Secondary endpoints included 
spirometric parameters, health status measured by the St Georges Respiratory Questionnaire (SGRQ), and study withdrawal. All-cause mortality was an efficacy and safety endpoint. The study failed to demonstrate a significant difference in the rate of exacerbations between the study groups $(62 \%$ for salmeterol/fluticasone and $59 \%$ for tiotropium). The probability of withdrawal from the study was $29 \%$ greater with tiotropium $(279 / 665 ; 42 \%)$ than with salmeterol/fluticasone $(232 / 658 ; 35 \% ; P=0.005)$. The SGRQ total score was statistically lower at 2 years in the salmeterol/fluticasone group compared to the tiotropium group ( -2.1 units; $95 \%$ CI $0.1-4.0 ; P=0.038)$, but failed to reach the minimum clinically relevant difference. Mortality was significantly lower in the salmeterol/ fluticasone group $(21 / 658 ; 3 \%)$ compared to the tiotropium group $(38 / 665 ; 6 \% ; P=0.032)$. Fatal cardiac events occurred in $1 \%(9 / 658)$ of the salmeterol/fluticasone group compared to $3 \%(19 / 665)$ in the tiotropium group. Pneumonia was more frequently reported in the salmeterol/ fluticasone group ( $8 \%$ ) compared to tiotropium (4\%). The hazard ratio for time to reported pneumonia was 1.94 (95\% CI 1.19-3.17; $P=0.008$ ) with salmeterol/fluticasone compared to tiotropium.

Lee et al conducted a nested case control study in a cohort of patients identified through the US Veterans Administration (VA) healthcare system diagnosed with COPD between October 1, 1999 and September 30, 2003. ${ }^{11}$ The objective of the study was to examine the association between respiratory medication use and the risk of death (both cardiovascular and respiratory) in this large population of patients with recently diagnosed COPD. Identified patients were followed through September 30, 2004 using the VA administrative databases, the Centers for Medicare and Medicaid Services databases, and the National Death Index Plus database. Patients were eligible for inclusion in the study if they were given a diagnosis of COPD at two or more outpatient visits within 12 months or had a hospital admission with a primary diagnosis of COPD. Patients had to be at least 45 years old at the time of their COPD diagnosis, have used the VA health system for 1 year prior to that diagnosis, and received respiratory medications.

Case patients were all individuals that died during follow-up identified using the VA Vital Status database. Of these, $40 \%$ were randomly selected to determine a specific cause of death. The cause of death was determined using the National Death Index Plus data from the National Center for Health Statistics. Deaths were classified as respiratory, cardiovascular, respiratory or cardiovascular and any-cause mortality. Control patients were alive at the time of case deaths and individually matched at a rate of 10:1 on the basis of gender, age, region of the country, and year of diagnosis. Exposure to respiratory medications was defined as having received one or more of these medications in the 6-month period between COPD diagnosis and the study end date or death. Respiratory medications included inhaled corticosteroids, ipratropium, long-acting beta-agonists, theophylline, and short-acting beta-agonists.

The study included 32,130 case patients and 320,501 control patients in the all-cause mortality analysis. Compared to no therapy or short-acting beta-agonists alone, both inhaled corticosteroids and long-acting beta-agonists were associated with reduced odds of all-cause mortality, ipratropium was associated with an increased risk of mortality, and theophylline had no significant effect on all-cause mortality. Adjusted (for covariates) odds ratios (ORs) for all-cause mortality were 0.80 (95\% CI $0.78-0.83)$ for inhaled corticosteroids, 0.92 (95\% CI 0.88-0.96) for long-acting beta-agonists, 1.05 (95\% CI 0.99-1.10) for theophylline, and 1.11 (95\% CI 1.08-1.15) for ipratropium.

In the cause specific mortality subgroup which included 11,897 patients, 2405 case patients had respiratory deaths and 3159 case patients had cardiovascular deaths. For respiratory deaths, theophylline significantly increased the risk of mortality (OR 1.71; 95\% CI 1.46-2.00). Respiratory deaths were less frequent with inhaled corticosteroids (OR 0.88; $95 \%$ CI $0.79-1.00$ ) but this trend was not statistically significant. Respiratory deaths were more frequent with long-acting beta-agonists (OR 1.12; 95\% CI 0.97 to 1.30 ) and tiotropium (OR 1.07; 95\% CI 0.96-1.20), but these trends were also not significant. Inhaled corticosteroids (OR 0.8; 95\% CI $0.72-0.88$ ) significantly reduced the risk of cardiovascular deaths, while the effects of long-acting beta-agonists (OR 0.97 ; 95\% CI 0.84-1.11) and theophylline (OR 1.16; 95\% CI 0.99-1.37) were not significantly significant. Ipratropium (OR 1.34; 95\% CI 1.22-1.47) significantly increased the risk of cardiovascular death. When both cardiovascular and respiratory deaths were combined, inhaled corticosteroids (OR 0.86; 95\% CI 0.8-0.93) significantly reduced mortality. Theophylline (OR 1.40; 95\% CI 1.25-1.57) and ipratropium (OR 1.27; 95\% CI 1.19-1.36) significantly increased combined respiratory and cardiovascular mortality. The effect of long-acting beta-agonists (OR 0.98 ; 95\% CI 0.89-1.09) on combined respiratory and cardiovascular mortality was not statistically significant.

Macie et al conducted a nested case-control analysis of subjects over the age of 35 years residing in the province 
of Manitoba, Canada who saw a physician for bronchitis, asthma, or COPD during 1996 through $2000 .{ }^{12}$ Cases were patients hospitalized during that time frame for supraventricular tachycardia, myocardial infarction, heart failure or stroke. Each case was matched according to gender, age and duration of insurance coverage with up to 10 controls that did not have that event. Exposure to respiratory drugs (inhaled beta-agonists, inhaled ipratropium, and inhaled corticosteroids) was documented in cases and controls. A conditional logistic regression was used in multivariate analysis which considered other respiratory drugs, respiratory diagnosis and visit frequency, and non-respiratory, non-cardiac comorbidities, and receipt of cardiovascular drugs.

In univariate analysis, beta-agonists, ipratropium, and inhaled corticosteroids were all associated with an increased frequency of cardiovascular hospitalizations. In the multivariate analysis, both beta-agonist and ipratropium use remained significantly associated with cardiac hospitalizations. However, the association between inhaled corticosteroids and cardiac hospitalizations was no longer significant. Inhaled corticosteroid use was actually associated with significantly fewer hospitalizations for supraventricular tachycardia, heart failure, and stroke. The use of cardiac drugs decreased the likelihood of hospitalization associated with beta-agonists and ipratropium. The addition of nonrespiratory and non-cardiac comorbidities did not affect the association between the bronchodilators and cardiac hospitalizations.

Guite et al followed a cohort of 2242 patients discharged from the hospital following an admission for asthma. ${ }^{13}$ Eighty-five deaths occurred during a 3-year follow-up of this cohort and were compared with a randomly selected group of 122 survivors from the same cohort. Deaths due to asthma (OR 4.04; 95\% CI 1.47-11.13), COPD (OR 7.75; 95\% CI 2.21-27.14), and cardiac causes (OR 3.55; 95\% CI 1.05-11.94) were more common in patients prescribed ipratropium. Asthma deaths secondary due to ipratropium remained significant even after adjustment for peak flow rates, presence or absence of COPD, cardiovascular co-morbidity, smoking, and age at onset of asthma. The use of inhaled corticosteroids was associated with a reduction in deaths due to asthma and COPD.

Ringbaek and Viskum identified a cohort of 827 patients with COPD and 273 patients with asthma. ${ }^{14}$ Over the course of follow-up, $65 \%$ of the COPD patients and $28 \%$ of the asthma patients died. Ipratropium use, after adjustment for $\mathrm{FEV}_{1}$, smoking, asthma medications, and cor pulmonale, was associated with a significant mortality risk in both
COPD (RR 1.6; 95\% CI 1.2-2.1) and asthma (RR 2.4; 95\% CI 1.2-5.0).

\section{Evidence that anticholinergics do not increase adverse cardiovascular outcomes}

A pooled safety analysis published in 2006 included adverse event data from 19 randomized placebo-controlled clinical trials treating 4435 patients with tiotropium and 3384 patients with placebo. ${ }^{15}$ The average duration of drug therapy exposure was 150 days with approximately two-thirds of patients receiving treatment for 6 months or less. The remaining 35\% of patients received therapy for up to 12 months. These trials confirmed the most common side effects of tiotropium to be dry mouth and urinary retention. Urinary retention occurred with tiotropium at a rate 10 times greater than placebo. However, the overall frequency of urinary retention with tiotropium was observed in 13 cases out of 3521 patients treated compared to one case out of 2469 patients treated with placebo. The most common serious adverse event was COPD exacerbation which occurred at a significantly lower rate with tiotropium than with placebo. More serious outcomes, such as all-cause mortality, cardiovascular mortality, and myocardial infarction did not occur more frequently with tiotropium. Compared to placebo, the relative risk of total mortality, cardiovascular mortality, and respiratory mortality with tiotropium were 0.76 (95\% CI 0.5-1.16), 0.57 (95\% CI 0.26-1.26), and 0.71 (95\% CI 0.29-1.74), respectively.

Tiotropium was compared to placebo in 5993 patients followed for 4 years in the Understanding Potential LongTerm Impacts on Function with Tiotropium (UPLIFT) trial. ${ }^{16}$ Eligible patients had to have a clinical diagnosis of COPD, be 40 years or older, have a smoking history of at least 10 packyears, a postbronchodilator $\mathrm{FEV}_{1}$ of $70 \%$ or less of predicted, and an $\mathrm{FEV}_{1}$ of $70 \%$ or less of the FVC. Patients with asthma, a history of pulmonary resection, use of supplemental oxygen for more than 12 hours per day, and a COPD exacerbation or respiratory infection in the 4 weeks prior to screening were excluded from the study. Patients were allowed to use previously prescribed respiratory medications other than anticholinergics. Any medication could be used during the management of an acute COPD exacerbation. Drug therapy used for smoking cessation was also allowed.

The two co-primary endpoints of the trial were the yearly rate of decline in the mean prebronchodilator and postbronchodilator $\mathrm{FEV}_{1}$ from day 30 of treatment until the end double-blind treatment with tiotropium and placebo. 
Secondary outcomes included the rate of decline in the mean FVC and slow vital capacity (SVC), health-related quality of life measured by the SGRQ, COPD exacerbations, COPD exacerbations resulting in hospitalization, and all-cause mortality and mortality due to lower respiratory conditions.

Patients were recruited from January 2003 through March 2004 with follow-up completed in February 2008. A total of 5993 patients were randomized with 2987 assigned to tiotropium and 3006 assigned to placebo. A greater number of patients failed to complete at least 45 months of treatment in the placebo group (45\%) compared to the tiotropium group (36\%) $(P<0.001)$. There were no significant differences in the baseline demographics and clinical characteristics between the two treatment groups.

There were no significant differences between treatment groups in the rate of decline in the $\mathrm{FEV}_{1}$ and $\mathrm{FVC}$ either before or after bronchodilation from day 30 to the end of the study. Tiotropium did significantly improve quality of life scores compared to placebo at all time points. A significantly greater proportion of patients had an improvement of 4 units or more in total SGRQ scores in the tiotropium group than in the placebo group at each annual follow-up interval. Tiotropium was associated with a significant delay in the time to the first exacerbation (16.7 months vs 12.5 months) compared to placebo. Tiotropium was also associated with a significant delay in the time to the first hospitalization for an exacerbation and the overall number of exacerbations compared to placebo. The total number of exacerbations leading to hospitalizations was infrequent and did not differ significantly between tiotropium and placebo.

Mortality data for patients with a follow-up through the active treatment period of 1440 days was available for $95 \%$ of patients. The hazard ratio for mortality through 1440 days was 087 (95\% CI $0.76-0.99 ; P=0.034)$. Mortality data for patients with a follow-up through the 1440 days of active treatment plus the 30 days of post-treatment follow-up (1470 days) was available for $75 \%$ of patents. Intention-to-treat mortality for patients with a follow-up of 1470 days was $14.9 \%$ in the tiotropium group and $16.5 \%$ in the placebo group (hazard ratio, $0.89 ; 95 \%$ CI $0.79-1.02$ ). The relative risk for serious adverse cardiac events for tiotropium vs placebo was 0.84 (95\% CI 0.73-0.98; $P<0.05)$. The relative risk of congestive heart failure (RR 0.59 ; 95\% CI $0.37-0.96$ ) and myocardial infarction (RR $0.71 ; 95 \%$ CI 0.52-0.99) was also significantly lower with tiotropium compared to placebo. The relative risk of stroke in the tiotropium vs placebo groups was not significantly different (RR 0.95; 95\% CI 0.70-1.29).
Serious adverse lower respiratory adverse events were less frequent with tiotropium compared to placebo (RR 0.84; 95\% CI 0.77-0.92; $P<0.05)$. COPD exacerbations, dyspnea, and respiratory failure were all significantly less common with tiotropium than with placebo.

Oba et al reanalyzed the studies included in the metaanalysis published by Singh et al incorporating the results of the UPLIFT study. ${ }^{8}$ These investigators also corrected the errors in the Singh meta-analysis previously described. In the updated meta-analysis, the composite risk of myocardial infarction, stroke, and cardiovascular death was no longer significant with the use of tiotropium compared to the control group (RR 1.00; 95\% CI 0.88-1.13; $P=0.97$ ). The composite risk remained significant for ipratropium compared to controls (RR 1.70; 95\% CI 1.19-2.42; $P=0.003$ ), but $90 \%$ of this effect was secondary to the results of the LHS. In addition, when only long-term trials were analyzed, the association between tiotropium and the composite risk of adverse cardiovascular outcomes was no longer statistically significant (RR 1.00; 95\% CI 0.88-1.1; $P=0.96$ ).

Several other studies have examined the relationship between anticholinergic use and mortality in COPD patients. Salpeter et al conducted a meta-analysis of 22 randomized controlled trials on beta-agonist (both short- and long-acting) and anticholinergic use in patients with COPD published between 1966 and December 2005. ${ }^{17}$ A total of 15,276 patients were included in these studies with a mean follow-up of 20 months and a mean study size of 694 patients. A total of 7 trials compared inhaled anticholinergics with placebo, 13 trials compared beta-agonists with placebo, and 7 trials compared anticholinergics with beta-agonists. Compared to placebo, anticholinergics reduced the risk of severe exacerbations by $33 \%$ (RR $0.67 ; 95 \%$ CI $0.53-0.86$ ) and respiratory deaths by $73 \%$ (RR 0.27 ; 95\% CI 0.09-0.81). Compared with placebo, beta-agonists did not significantly reduce severe exacerbations (RR 1.08; 95\% CI 0.61-1.95) and significantly increased the risk of respiratory deaths (RR 2.47; 95\% CI 1.12-45). When anticholinergics were compared to betaagonists, beta-agonist use was associated with an excess risk of exacerbation requiring study withdrawal (RR 2.02; 95\% CI 1.39-2.93) and an excess risk of exacerbation requiring hospitalization (RR 1.95; 95\% CI 1.06-3.59). As only two of the seven comparative trials reported mortality, conclusions about relative mortality risk between anticholinergics and beta-agonists could not be reached.

Rodrigo et al also conducted a meta-analysis of randomized controlled trials comparing long-acting beta-agonists against either placebo or anticholinergic inhalers. ${ }^{18}$ Studies 
had to include patients older than 35 years of age with a diagnosis of COPD (bronchitis or emphysema) who received a long-acting beta-agonist alone or in combination with an inhaled corticosteroid for at least 1 month in duration. Studies had to report the frequency of COPD exacerbations resulting in study withdrawal or hospitalization, all-cause mortality, and respiratory mortality. Secondary outcomes included changes in $\mathrm{FEV}_{1}$ and the SGRQ and the need for rescue bronchodilator. A total of 88 studies were identified of which 27 studies met the inclusion criteria. A total of 20,527 patients were included in these studies. Compared to placebo, long-acting beta-agonists significantly reduced the relative risk of severe exacerbations (RR 0.78; 95\% CI 0.67-0.91). Compared to placebo, long-acting beta-agonists had no significant effect on the relative risk of respiratory deaths (RR 1.09; 95\% CI 0.45-2.64). Addition of inhaled corticosteroids to long-acting beta-agonists reduced the risk of respiratory death compared to beta-agonists alone (RR 0.35; 95\% CI 0.14-0.93). Compared to placebo, long-acting beta-agonists demonstrated significant benefits regarding airflow limitation, health-related quality of life, and use of rescue medications. In a limited number of studies, tiotropium significantly decreased the incidence of severe COPD exacerbations compared to long-acting beta-agonists (RR 0.52; 95\% CI 0.31-0.87).

A population-based cohort study was conducted in 3 counties in Denmark which used a National Health Service to provide medical care to its residents. ${ }^{19}$ Patients over 40 years of age hospitalized for COPD between 1/1/1977 to 12/21/2003 were identified. Cox regression was used to compute incidence rate ratios (RR) and 95\% CI for hospitalization and death between 1/1/2002 and 12/31/2003 associated with tiotropium use compared to periods of nonuse, controlling for a variety of confounders. A total of 2870 tiotropium users and 7733 non-users were identified with an average follow-up of 18 to 24 months. The relative risk for total and cause-specific hospitalizations was not increased during tiotropium use except for COPD hospitalizations (RR 1.52; 95\% CI 1.29-1.79). Total and cause-specific mortality was not significantly increased during tiotropium use.

A retrospective cohort study was performed using linked data from the Canadian Institute for Health Information, the Ontario Drug Benefit Program, the Ontario Health Insurance Plan, and the Ontario Registered Persons database to evaluate the effect of ipratropium on mortality rates in patients over the age of 65 years discharged from the hospital with a diagnosis of COPD or asthma between 4/1/1992 and 3/31/1997. ${ }^{20}$ A total of 32,292 patients were included in the analysis of which 49\% received ipratropium within 90 days of discharge. After adjustment for age, gender, and other comorbidities, there was no significant association between the use of ipratropium and mortality (RR 1.03; 95\% CI 0.98-1.08) in patients with COPD. There was, however, a significant increase in the risk of mortality associated with the use of ipratropium (RR 1.24; 95\% CI 1.11-1.39) in patients with asthma.

A cohort comparison using The Health Information Network in the United Kingdom (UK THIN) compared the risk of mortality and respiratory and cardiac adverse events in patients using tiotropium compared to patients using a long-acting beta-agonist during the time period from November 2002 until June 2004. ${ }^{21}$ The study population was not restricted to COPD. A total of 1061 tiotropium users and 1801 long-acting beta-agonist users were identified and followed for an average of 5 months. Total mortality and most cardiac event rates were not significantly different between the two treatment groups. There was, however, a significant decrease in the risk of heart failure among tiotropium users (HR 0.65; 95\% CI 0.29-1.51) compared to long-acting betaagonists. The risk of respiratory events (COPD exacerbations and pneumonia) was not significantly different between the treatment groups. There was, however, a significant reduction in the risk of asthma exacerbations among tiotropium users (HR 0.41; 95\% CI 0.26-0.64) compared to long-acting beta-agonist users.

\section{Commentary}

Evidence-based guidelines are only as good as the evidence used to support their recommendations. The strongest available evidence is randomized controlled trials that have adequate power to detect significant differences in the outcomes they seek to evaluate. An inherent disadvantage of controlled trials is that they limit inclusion to patients with minimal comorbidities and other confounding characteristics. They also typically include patients who by definition are compliant. In other words, patients enrolled in controlled trials may not be representative of patients actually treated in a "real world" setting. Another major limitation of randomized controlled trials in COPD is the failure to collect outcome data on a strict intention-to-treat basis. In many COPD trials, patients' study participation ends when the study intervention ends. When strict intention-to-treat data analysis is used, an important number of adverse cardiac and respiratory events occur after study treatment discontinuation. In one trial analyzed by Kesten et al premature treatment discontinuation occurred in a substantially greater number of placebo patients compared to the active comparator (tiotropium). ${ }^{22}$ 
If outcomes were limited to only those occurring during treatment, the results would have found a higher incidence of adverse clinical events in the active treatment group compared to placebo. By using strict intention-to-treat with follow-up for the pre-specified time period, patients receiving tiotropium actually had a significantly lower incidence of adverse clinical outcomes compared to placebo.

Other evidence which may be considered in the development of treatment guidelines include meta-analyses, observational (cohort or case-control) studies, and consensus opinion or standards of care. None of these methodologies carry the weight upon which a class I treatment recommendation can be based. In addition, these methodologies cannot be used to prove or disprove hypotheses. A meta-analysis, when conducted properly, can only be used to generate a hypothesis. There are several examples of meta-analyses which indicated effectiveness of a particular treatment which was subsequently disproved by an adequately powered controlled trial. ${ }^{23,24}$

There have been 15 publications that have evaluated an association between inhaled anticholinergics and cardiovascular safety in patients with COPD (Table 1). The number of publications observing an adverse cardiovascular effect of inhaled anticholinergics is roughly equal to the number of studies failing to document the association. Unfortunately, the quality of the evidence evaluating the cardiovascular risk of inhaled anticholinergic agents in patients with COPD is generally poor. Only three of the 15 publications were randomized controlled trials while the remaining studies included 5 meta-analyses, 2 case-control studies, and 5 cohort observations.

The ultimate question is why there is such wide disparity in the findings among the published data concerning the cardiovascular risk of inhaled anticholinergic agents in patients with COPD. In general, case-control and cohort trials are limited by their inability to control for baseline differences among treatment groups with regard to smoking history, lung function, and disease severity. Dose-effect relationships linking anticholinergic use with adverse cardiovascular outcomes are difficult to establish in these studies due to the inefficient and crude measures used to establish adherence to assigned drug regimens.

Meta-analyses, although methodologically more robust than case-control or cohort observations because they pool the results of randomized controlled trials, have significant

Table I Publications evaluating the association between inhaled anticholinergics and adverse cardiovascular outcomes

\begin{tabular}{|c|c|c|c|c|c|c|c|}
\hline \multicolumn{4}{|c|}{$\begin{array}{l}\text { Positive association between anticholinergics and adverse } \\
\text { cardiovascular outcomes }\end{array}$} & \multicolumn{4}{|c|}{$\begin{array}{l}\text { Negative association between anticholinergic and adverse } \\
\text { cardiovascular outcomes }\end{array}$} \\
\hline Author & $\begin{array}{l}\text { Year } \\
\text { published }\end{array}$ & Study design & Drug evaluated & Author & $\begin{array}{l}\text { Year } \\
\text { published }\end{array}$ & Study design & Drug evaluated \\
\hline \multirow[t]{2}{*}{$\begin{array}{l}\text { Anthonisen } 9 \\
\text { (LHS) }\end{array}$} & 2002 & $\begin{array}{l}\text { Prospective, } \\
\text { randomized, } \\
\text { placebo-controlled, } \\
\text { double-blind }\end{array}$ & Ipratropium vs placebo & $\mathrm{Oba}^{8}$ & 2008 & Meta-analysis & $\begin{array}{l}\text { Re-analysis of } \\
\text { Singh }^{7} \text { meta-analysis }\end{array}$ \\
\hline & & & & Tashkin $^{16}$ & 2008 & $\begin{array}{l}\text { Prospective, randomized, } \\
\text { placebo-controlled, } \\
\text { double-blind }\end{array}$ & $\begin{array}{l}\text { Tiotropium vs } \\
\text { placebo }\end{array}$ \\
\hline $\begin{array}{l}\text { Wedzicha }{ }^{10} \\
\text { (INSPIRE) }\end{array}$ & 2008 & $\begin{array}{l}\text { Prospective, } \\
\text { randomized, } \\
\text { double-blind }\end{array}$ & $\begin{array}{l}\text { Tiotropium vs } \\
\text { salmeterol/fluticasone }\end{array}$ & Kesten ${ }^{15}$ & 2006 & Pooled safety analysis & $\begin{array}{l}\text { Tiotropium vs } \\
\text { placebo }\end{array}$ \\
\hline Singh ${ }^{7}$ & 2008 & Meta-analysis & $\begin{array}{l}\text { Ipratropium or } \\
\text { tiotropium vs placebo } \\
\text { or LABA or LABA-ICS }\end{array}$ & Salpeter ${ }^{17}$ & 2006 & Meta-analysis & $\begin{array}{l}\text { Ipratropium or } \\
\text { tiotropium vs } \\
\text { LABA or LABA-ICS }\end{array}$ \\
\hline Lee $^{\prime \prime}$ & 2008 & $\begin{array}{l}\text { Nested case } \\
\text { control }\end{array}$ & $\begin{array}{l}\text { Ipratropium vs LABA, } \\
\text { ICS or theophylline }\end{array}$ & Rodrigo $^{18}$ & 2007 & Meta-analysis & $\begin{array}{l}\text { Ipratropium or } \\
\text { tiotropium vs } \\
\text { LABA or LABA-ICS }\end{array}$ \\
\hline Macie $^{12}$ & 2008 & $\begin{array}{l}\text { Nested case } \\
\text { control }\end{array}$ & $\begin{array}{l}\text { Ipratropium vs } \\
\text { LABA or ICS }\end{array}$ & de Luise ${ }^{19}$ & 2007 & Observational cohort & Tiotropium \\
\hline Guite $^{13}$ & 1999 & $\begin{array}{l}\text { Observational } \\
\text { cohort }\end{array}$ & $\begin{array}{l}\text { Ipratropium vs } \\
\text { LABA or ICS }\end{array}$ & $\operatorname{Sin}^{20}$ & 2000 & Observational cohort & Ipratropium \\
\hline Ringback $^{14}$ & 2003 & $\begin{array}{l}\text { Observational } \\
\text { cohort }\end{array}$ & $\begin{array}{l}\text { Ipratropium vs } \\
\text { LABA or ICS }\end{array}$ & $\operatorname{Jara}^{21}$ & 2007 & Observational cohort & $\begin{array}{l}\text { Tiotropium vs } \\
\text { LABA }\end{array}$ \\
\hline
\end{tabular}

Abbreviations: LABA, long-acting beta-agonist; ICS, inhaled corticosteroid. 
limitations. The major limitation of the meta-analyses evaluating the relationship between anticholinergic use and cardiovascular risk is the exclusion of a large number of trials solely on the basis that cardiovascular endpoints were not reported. In the meta-analysis conducted by Singh et al, 71 of the 103 studies considered for inclusion were ultimately excluded because cardiovascular endpoints were not reported. ${ }^{7}$ This is also true for the meta-analyses that failed to establish a relationship between anticholinergic use and adverse cardiovascular events. Another limitation of the published meta-analyses is that cardiovascular events reported in the pooled studies were not adequately adjudicated by a safety and data monitoring board. The primary endpoints of the included studies were outcomes other than mortality. Reporting of adverse cardiovascular outcomes may have inherently been incomplete or inaccurate.

Ultimately, adequately powered randomized controlled trials with adjudication of cardiovascular events are needed to assess the cardiovascular safety of anticholinergic agents in patients with COPD. Three randomized controlled trials have evaluated the cardiovascular safety of anticholinergic agents in patients with COPD. ${ }^{9,10,16}$ The first randomized controlled trial assessing the cardiovascular risk of an inhaled anticholinergic in patients with mild to moderate lung function impairment was the LHS published in 2002. ${ }^{9}$ As previously discussed, the LHS observed a weak relationship between assignment to ipratropium use and a higher risk of death and hospitalization secondary to cardiovascular disease. The failure to adjust the observed $P$ values for multiple comparisons and to establish a dose-effect relationship between ipratropium use and cardiac mortality prevented the LHS investigators from reaching the conclusion that ipratropium was absolutely associated with an adverse effect on cardiovascular mortality.

Both of the remaining randomized controlled trials evaluating the cardiovascular safety of anticholinergic agents included tiotropium (Table 2). The UPLIFT trial was an adequately designed randomized placebo-controlled trial evaluating the effect of tiotropium on the rate of decline of $\mathrm{FEV}_{1}$ in patients with moderate-to-very severe COPD. ${ }^{16}$ Tiotropium failed to slow the rate of decline in spirometric parameters, but did significantly improve quality of life scores, reduce the frequency of exacerbations, prolong the time to the first hospitalization for an exacerbation, and reduce the frequency of respiratory failure. Tiotropium was associated with a lower all-cause mortality rate, but this failed to reach statistical significance (HR 0.89; 95\% CI 0.79-1.02) when follow-up through 1470 days was used. The incidence rate of serious cardiac (RR 0.84; 95\% CI 0.73-0.98) and lower respiratory (RR 0.84; 95\% CI 0.77-0.94) adverse events was significantly lower with tiotropium than placebo.

Table 2 Comparisons of randomized controlled trials of bronchodilators in patients with COPD

\begin{tabular}{|c|c|c|c|c|c|c|c|c|}
\hline & \multicolumn{2}{|c|}{ INSPIRE $^{10}$} & \multicolumn{2}{|l|}{ UPLIFT $^{16}$} & \multicolumn{4}{|l|}{ TORCH $^{25}$} \\
\hline & SFC & TIO & TIO & PLAC & SFC & $\mathbf{S}$ & $\mathbf{F}$ & PLAC \\
\hline Enrolled & 658 & 665 & 2987 & 3006 & 1523 & $|52|$ & 1534 & 1524 \\
\hline Withdrew & 232 (35\%) & 279 (42\%) & 1099 (37\%) & I 358 (45\%) & $522(34 \%)$ & $561(37 \%)$ & 587 (38\%) & 673 (44\%) \\
\hline Duration & \multicolumn{2}{|c|}{2 years } & \multicolumn{2}{|c|}{4 years } & \multicolumn{4}{|c|}{3 years } \\
\hline Age & 64 & 65 & 64 & 64 & 65 & 65 & 65 & 65 \\
\hline$\%$ men & 81 & 84 & 75 & 74 & 76 & 76 & 75 & 76 \\
\hline $\begin{array}{l}\text { Post-bronch } \\
\mathrm{FEV}_{\text {, }}\end{array}$ & 39 & 39 & 47 & 47 & 44 & 44 & 44 & 44 \\
\hline Smokers & 38 & 38 & 29 & 30 & 43 & 43 & 43 & 43 \\
\hline $\begin{array}{l}\text { Smoking history } \\
\text { (pack-year) }\end{array}$ & 41.3 & 39.5 & 49 & 48 & 49 & 49 & 49 & 47 \\
\hline SGRQ & 48.6 & 49.1 & 45.7 & 46.0 & 49 & 50 & 49 & 49 \\
\hline On ICS & 48 & 51 & 62 & 62 & 47 & 45 & 47 & 51 \\
\hline $\begin{array}{l}\text { All cause } \\
\text { mortality }\end{array}$ & $21(3 \%)$ & $38(6 \%)$ & $14.9 \%$ & $16.5 \%$ & $12.6 \%$ & $13.5 \%$ & $16.0 \%$ & $15.2 \%$ \\
\hline $\begin{array}{l}\text { Cardiac } \\
\text { death }\end{array}$ & $9(1 \%)$ & $19(3 \%)$ & 26 (0.9\%) & $32(I .1)$ & $4 \%$ & $3 \%$ & $4 \%$ & $5 \%$ \\
\hline $\begin{array}{l}\text { History of } \\
\text { CV disease }\end{array}$ & $9(3 \%)$ & $24(8 \%)$ & NR & NR & NR & NR & NR & NR \\
\hline
\end{tabular}

Abbreviations: SFC, salmeterol plus fluticasone combination; TIO, tiotropium; PLAC, placebo; S, salmeterol; F, fluticasone; ICS, inhaled corticosteroids; SGRQ, St George's Respiratory Questionnaire. 
The INSPIRE trial, an adequately designed 2-year trial primarily designed to compare to the impact of the combination of salmeterol/fluticasone and tiotropium on COPD exacerbations, found that neither treatment was superior with regard to the frequency of exacerbations (Table 2). ${ }^{10}$ The salmeterol/fluticasone combination was associated with significantly lower rates of study withdrawal (29\% less) and all-cause mortality ( $52 \%$ reduction) compared to tiotropium. In patients with baseline cardiovascular disease, cardiac death occurred in $3 \%$ of the salmeterol/fluticasone group and $8 \%$ of the tiotropium group. The reduction in cardiovascular mortality was offset in part by a 2-fold increase in the risk of pneumonia in the salmeterol/fluticasone group (8\%) compared to the tiotropium group (4\%). The INSPIRE trial was not designed as a mortality trial, lacked adequate adjudication of fatal outcomes, and lacked a full intention-to-treat analysis of the data. The failure to follow patients after treatment discontinuation and a potential bias introduced during the run-in period render the mortality results of the INSPIRE trial difficult to interpret.

The Towards a Revolution in COPD Health (TORCH) trial was a 3 year randomized placebo-controlled trial comparing fluticasone alone, salmeterol alone or their combination in 6112 COPD patients (Table 2) ${ }^{25}$ Although this trial did not include an anticholinergic agent, the results are illustrative of the potential difficulty in demonstrating a mortality benefit of drug therapy in patients with COPD. The primary outcome of the trial was all-cause mortality comparing the combination of salmeterol plus fluticasone against placebo. Compared to placebo, the combination treatment group reduced exacerbations, improved health status, and improved spirometric measures. All-cause mortality was $12.6 \%$ in the combination group, $13.5 \%$ in the salmeterol monotherapy group, $15.2 \%$ in the placebo group, and $16.0 \%$ in the fluticasone group. The hazard ratio for the combination group was 0.825 (95\% CI 0.68 to 1.00 ) compared to placebo $(P=0.052)$. Hence, no randomized trial has been able to demonstrate a mortality benefit of drug therapy in patients with COPD.

The results of the placebo-controlled UPLIFT and TORCH trials suggest that similar outcomes, including all-cause mortality, are achieved when patients with COPD are treated either with tiotropium or a combination of salmeterol/fluticasone. The INSPIRE trial, although methodologically flawed, suggests a significant mortality benefit of salmeterol/fluticasone over tiotropium. Are the results of the INSPIRE trial, the only randomized controlled trial that clearly favors the use of salmeterol/fluticasone over tiotropium, of sufficient weight to influence clinical decisions concerning the use of tiotropium? Are the results of the INSPIRE trial of sufficient weight to change the current treatment guidelines which do not make a specific recommendation for a specific bronchodilator?

Evaluation of the study designs, patient populations, and results of the UPLIFT, TORCH, and INSPIRE offer little evidence to suggest that any of these three trials were seriously flawed. One difference among these three trials that has raised some questions is the reported absolute mortality rate. The INSPIRE trial reported on overall mortality rate of about $4.5 \%$ with a 2 -year follow-up, while the TORCH and UPLIFT trials reported overall mortality rates of approximately $13 \%$ to $16 \%$ with 3 - to 4 -year follow-ups. The severity of illness of enrolled patients do not appear to be dramatically different, although the study with the lowest mortality (INSPIRE) had the lowest mean baseline post-bronchodilator $\mathrm{FEV}_{1}(38 \%$ vs $44 \%-47 \%)$. One major limitation of each of these trials is the failure to report the incidence of baseline major co-morbidities. The numbers of patients with prior coronary heart disease and other co-morbidities is not disclosed. It is interesting to note that in the INSPIRE trial, mortality results for patients with a history of cardiac disease are reported, but the incidence of cardiac disease at baseline is unknown. It is clear given the disparate mortality outcomes between the three randomized trials that attempts to compare studies enrolling different patient populations and reach valid conclusions based on those comparisons is futile.

Following the FDA's early communication and the publication of the meta-analysis by Singh et al the American College of Chest Physicians convened a task force of pulmonologists with expertise on the use of inhaled bronchodilators in patients with COPD. The task force reached four areas of agreement. (1) Smoking cessation remains the only treatment proven to slow the progression of COPD in all stages and reduced the risk of death from cardiovascular disease. (2) More patients with severe COPD die from cardiovascular disease (heart attack or stroke) than from respiratory failure. (3) All of the risks, benefits, and costs of the inhaled medications used for COPD need to be assessed when they are prescribed and at each follow-up visit. Decisions about changes in the use of inhaled anticholinergics in patients with COPD should consider the patient's symptoms, comorbidities, patient comfort level, and potential benefit versus risk. (4) Prospective, adequately powered randomized clinical trials, designed and monitored by the NHLBI and FDA, should be conducted to provide more evidence regarding the safety of tiotropium. The goal of these studies should 
be to determine the subsets of patients with COPD at the highest risk of adverse cardiovascular events. The studies should include adjudication of the cardiovascular events and represent the patients who are treated with these drugs in a real world setting.

\section{Disclosures}

Drs Morrow and Schuller are on the Boehringer-Ingelheim speakers' bureau. Drs Hilleman and Malesker have no conflicts to disclose.

\section{References}

1. Global Initiative for Chronic Obstructive Lung Disease (GOLD). Global strategy for the diagnosis, management, and prevention of chronic obstructive pulmonary disease. Available at http://www. goldcopd.com/Guidelineitem.asp?I1=2\&12=1\&intId=989. Accessed March, 2009.

2. Rabe KF, Hurd S, Anzueto A, et al. Global strategy for the diagnosis, management and prevention of Chronic Obstructive Pulmonary Disease: GOLD executive summary. Am J Respir Crit Care Med. 2007;176:532-555.

3. American Thoracic Society/European Respiratory Society Task Force. Standards for the diagnosis and management of patients with COPD. Version 1.2. Available at http://www.thoracic.org/go/copd. Accessed March 2009

4. O'Donnell DE, Aaron S, Bourbeau J, et al. Canadian thoracic society recommendations for management of chronic obstructive pulmonary disease. Can Resp J. 2003;10:11A-65A.

5. Chronic Obstructive Pulmonary Disease. National clinical guideline on management of chronic obstructive pulmonary disease in adults in primary and secondary care. Thorax. 2004;59:1-232.

6. US Food and Drug Administration. Early communication about an ongoing safety review of tiotropium (marketed as Spiriva Handihaler). Available at http://www.fda.gov/cder/drug/early_comm/tiotropium. htm. Accessed August 5, 2008.

7. Singh S, Loke YK, Furberg CD. Inhaled anticholinergics and risk of major adverse cardiovascular events in patients with chronic obstructive pulmonary disease. A systematic review and meta-analysis. JAMA. 2008;300:1439-1450.

8. Oba Y, Zaza T, Thameem DM. Safety, tolerability, and risk benefit analysis of tiotropium in COPD. Int J COPD. 2008;3:575-584.

9. Anthonisen MNR, Connett JE, Enright PF, et al. Hospitalization and mortality in the Lung Health Study. Am J Respir Crit Care Med. 2002;166:333-339.
10. Wedzicha JA, Calverley PM, Seemungal TA, for the INSPIRE Investigators. The prevention of COPD exacerbations by salmeterol/ fluticasone propionate or tiotropium bromide. Am J Respir Crit Care Med. 2008;177:19-26.

11. Lee TA, Pickard AS, Au DH, Bartle B, Weiss K. Risk for death associated with medications for recently diagnosed chronic obstructive pulmonary disease. Ann Int Med. 2008;149:380-389.

12. Macie C, Wooldrage K, Manfreda J, Anthonisen N. Cardiovascular morbidity and the use of inhaled bronchodilators. Int J Chron Obstruct Pulmon Dis. 2008;3(1):163-169.

13. Guite HF, Dundos R, Burney PGI. Risk factors for death from asthma, chronic obstructive pulmonary disease, and cardiovascular disease after a hospital admission for asthma. Thorax. 1999;54:301-307.

14. Ringback T, Viskum K. Is there any association between inhaled ipratropium and mortality in patients with COPD and asthma? Respir Med. 2003;97:264-272.

15. Kesten S, Jara M, Wentworth C, Lanes S. Pooled clinical trial analysis of tiotropium safety. Chest. 2006;130:1695-1703.

16. Tashkin DP, Celli B, Senn SDB, et al. A 4-year trial of tiotropium in Chronic Obstructive Pulmonary Disease. N Engl J Med. 2008;359: 1543-1554.

17. Salpeter SR, Buckley NS, Salpeter EE. Meta-analysis: anticholinergics, but not beta-agonists, reduce severe exacerbations and respiratory mortality in COPD. J Gen Int Med. 2006;21:1011-1019.

18. Rodrigo GJ, Nannini LJ. Tiotropium for the treatment of stable chronic obstructive pulmonary disease: a systematic review with meta-analysis. Pulm Pharmacol Ther. 2007;20:495-502.

19. de Luise C, Lanes SF, Jacobsen J, Petersen L, Sorensen HT. Cardiovascular and respiratory hospitalizations and mortality among users of tiotropium in Denmark. Eur J Epidem. 2007;22:267-272.

20. Sin DD, Tu JV. Lack of association between ipratropium bromide and mortality in elderly patients with chronic obstructive airway disease. Thorax. 2000;55:194-197.

21. Jara M, Lanes SF, Wentworth III C, May C, Kesten S. Inhaled bronchodilators. A cohort study using the UK THIN primary care database. Drug Saf. 2007;30:1151-1160.

22. Kesten S, Plautz M, Piquette CA, Habib MP, Niewoehner DE. Premature discontinuation of patients: a potential bias in COPD clinical trials. Eur Respir J. 2007;30:898-906.

23. Higgins JP, Spiegelhalter DJ. Being sceptical about meta-analysis: A Bayesian perspective on magnesium trials in myocardial infarction. Int J Epidemiol. 2002;31:96-104.

24. Dens J, Desmet W, Piessens J. An updated meta-analysis of calcium channel blockers in the prevention of restenosis after coronary angioplasty. Am Heart J. 2003;145:404-408.

25. Calverley PMA, Anderson JA, Celli B, et al. Salmeterol and fluticasone propionate and survival in chronic obstructive pulmonary disease $N E n g l$ J Med. 2007;356:775-789.
International Journal of COPD

\section{Publish your work in this journal}

The International Journal of COPD is an international, peer-reviewed journal of therapeutics and pharmacology focusing on concise rapid reporting of clinical studies and reviews in COPD. Special focus is given to the pathophysiological processes underlying the disease, intervention programs, patient focused education, and self management protocols.

\section{Dovepress}

This journal is indexed on PubMed Central, MedLine and CAS. The manuscript management system is completely online and includes a very quick and fair peer-review system, which is all easy to use. Visit http://www.dovepress.com/testimonials.php to read real quotes from published authors. 